\title{
NUMERICAL MODELING OF SPRAY COMBUSTION WITH AN UNSTRUCTURED-GRID METHOD
}

\author{
H.M. Shang, Y.S. Chen, P. Liaw and M.H. Shih \\ Engineering Sciences, Inc., Huntsville, AL \\ and \\ T.S. Wang \\ NASA/Marshall Space Flight Center, Huntsville, AL
}

\begin{abstract}
The present unstructured-grid method follows strictly the basic finite volume forms of the conservation laws of the governing equations for the entire flow domain. High-order spatially accurate formulation has been employed for the numerical solutions of the Navier-Stokes equations. A two-equation $k-\varepsilon$ turbulence model is also incorporated in the unstructured-grid solver. The convergence of the resulted linear algebraic equation is accelerated with preconditioned Conjugate Gradient method. A statistical spray combustion model has been incorporated into the present unstructured-grid solver. In this model, spray is represented by discrete particles, rather than by continuous distributions. A finite number of computational particles are used to predict a sample of total population of particles. Particle trajectories are integrated using their momentum and motion equations and particles exchange mass, momentum and energy with the gas within the computational cell in which they are located. The interaction calculations are performed simultaneously and eliminate global iteration for the two-phase momentum exchange. A transient spray flame in a high pressure combustion chamber is predicted and then the solution of liquid-fuel combusting flow with a rotating cup atomizer is presented and compared with the experimental data. The major conclusion of this investigation is that the unstructured-grid method can be employed to study very complicated flow fields of turbulent spray combustion. Grid adaptation can be easily achieved in any flow domain such as droplet evaporation and combustion zone. Future applications of the present model can be found in the full three-dimensional study of flow fields of gas turbine and liquid propulsion engine combustion chambers with multi-injectors.
\end{abstract}



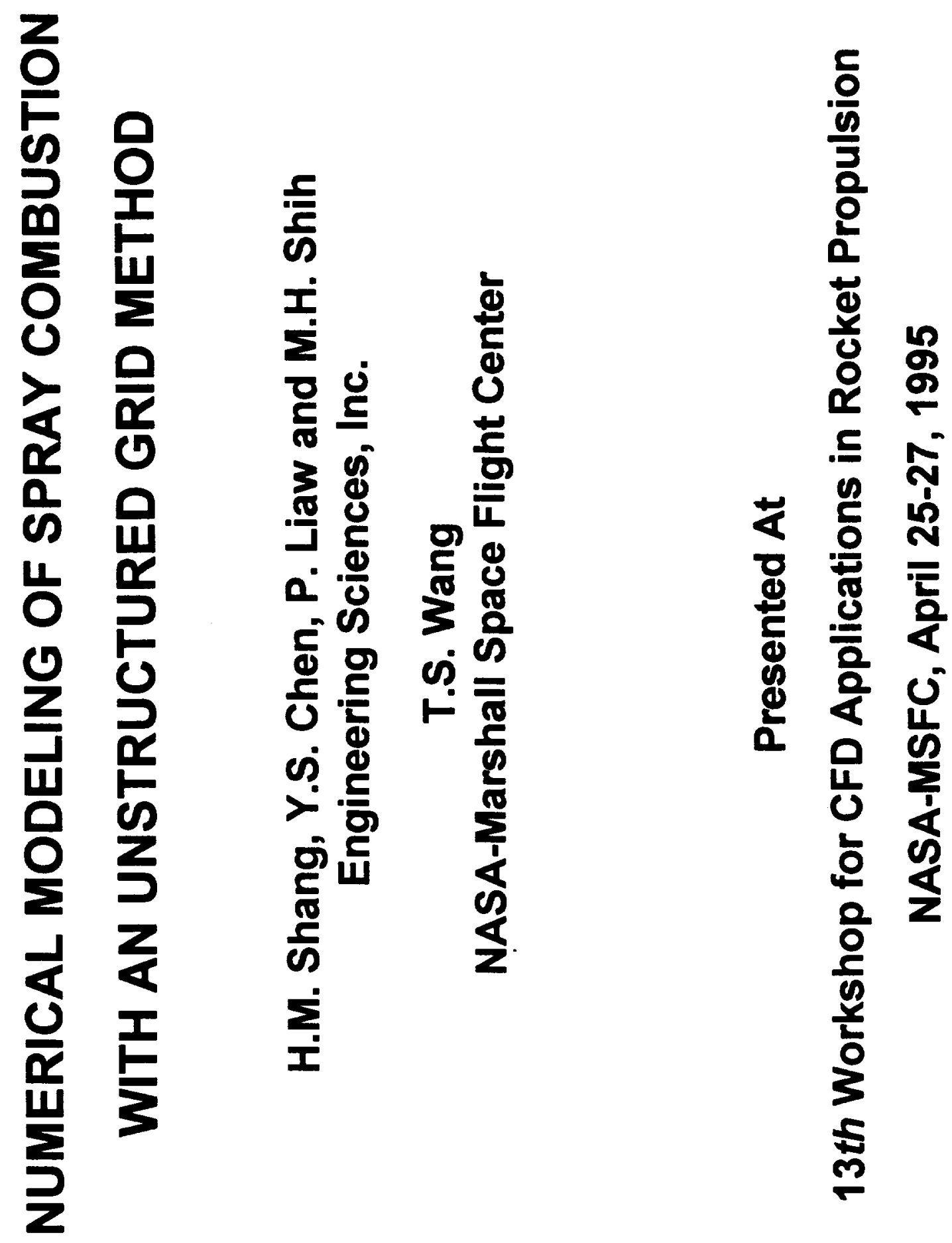

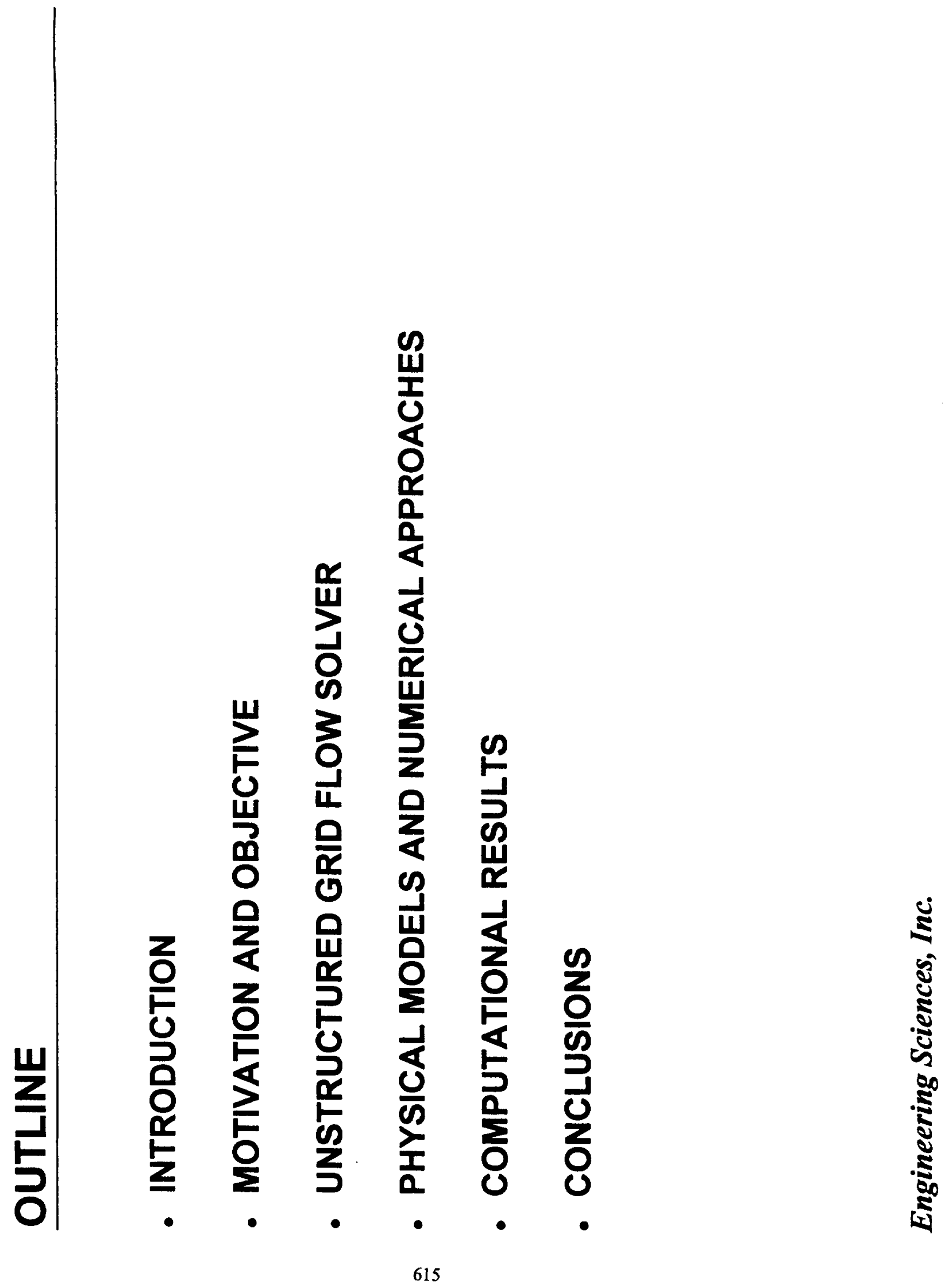


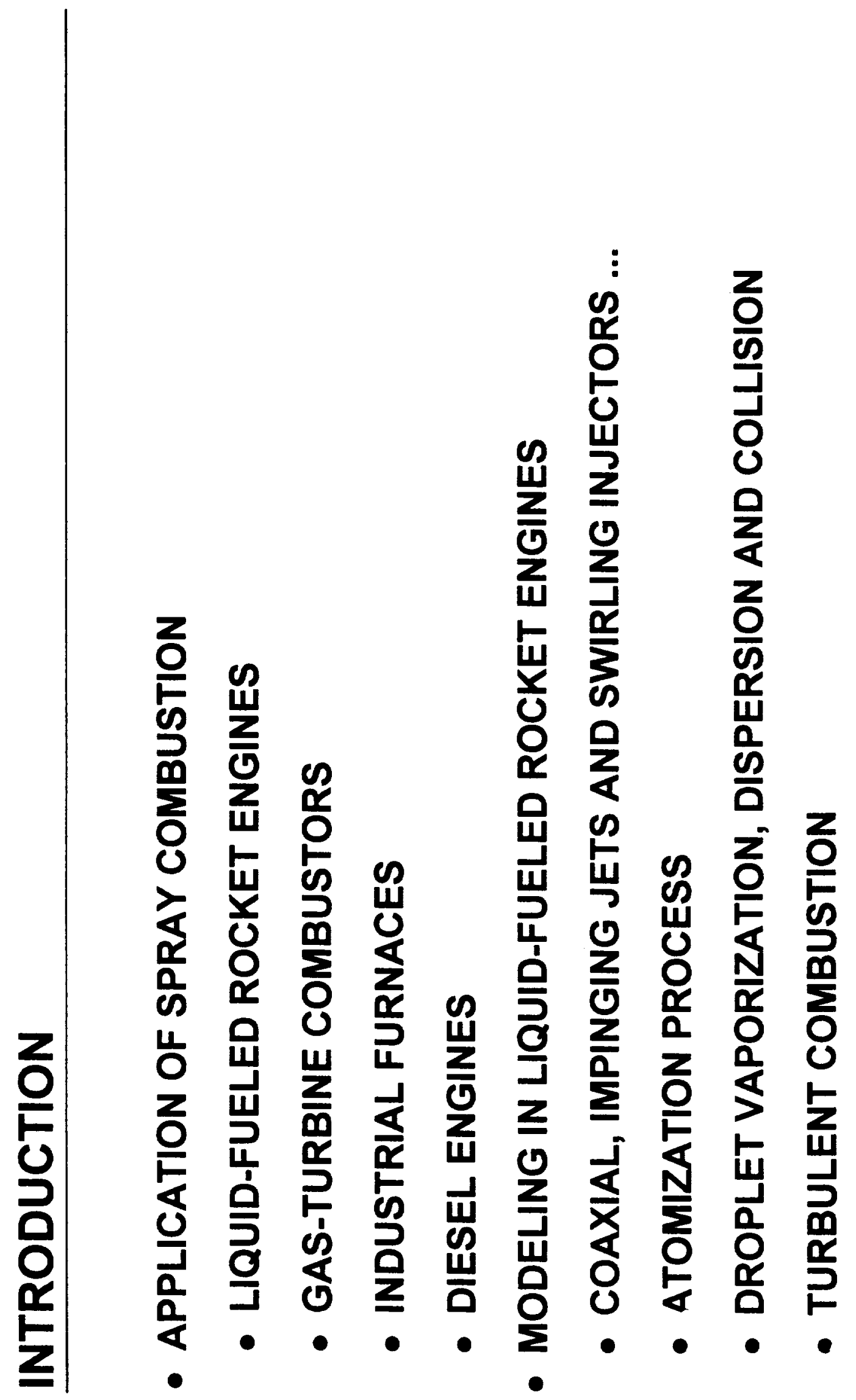

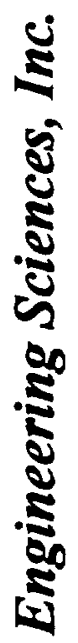



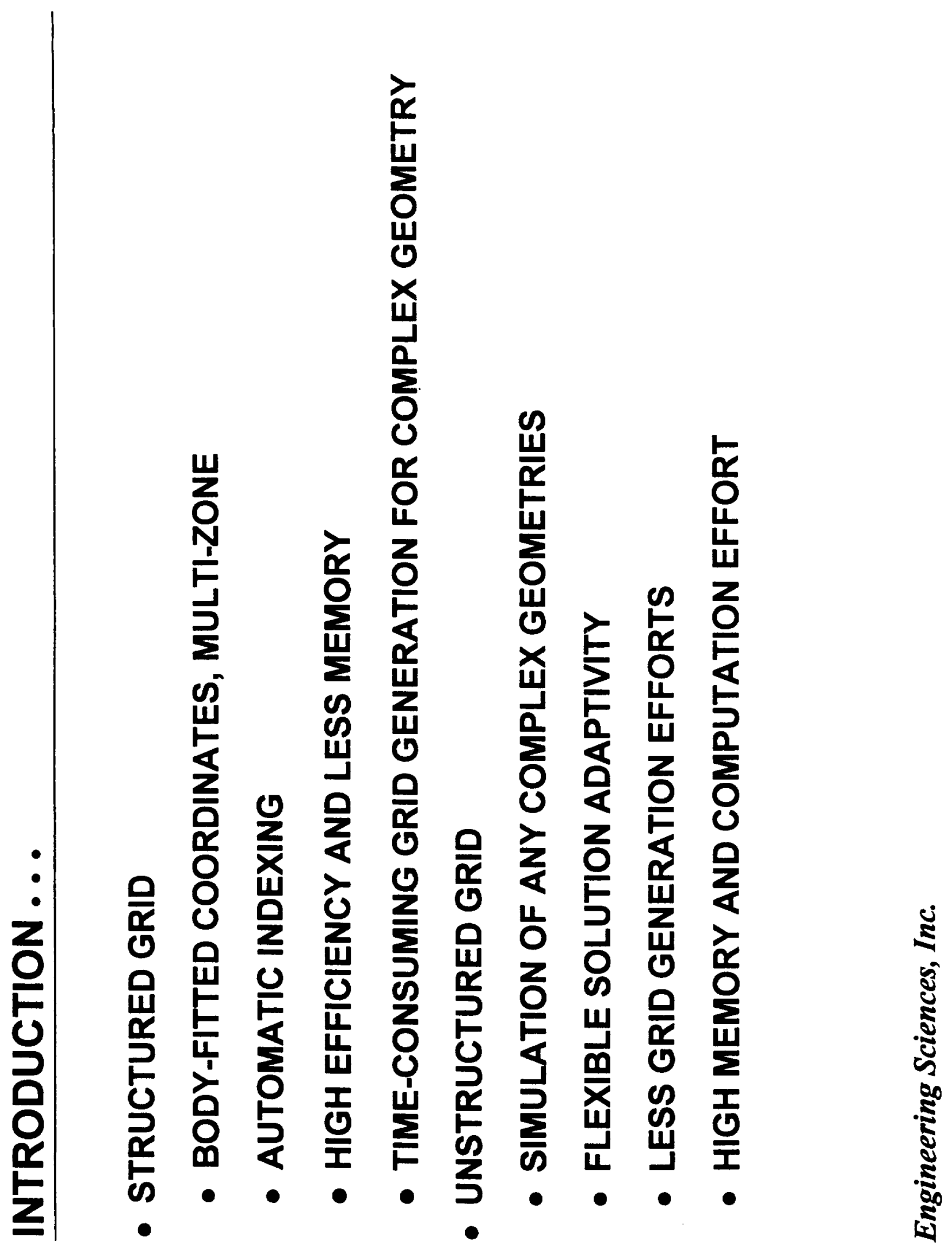


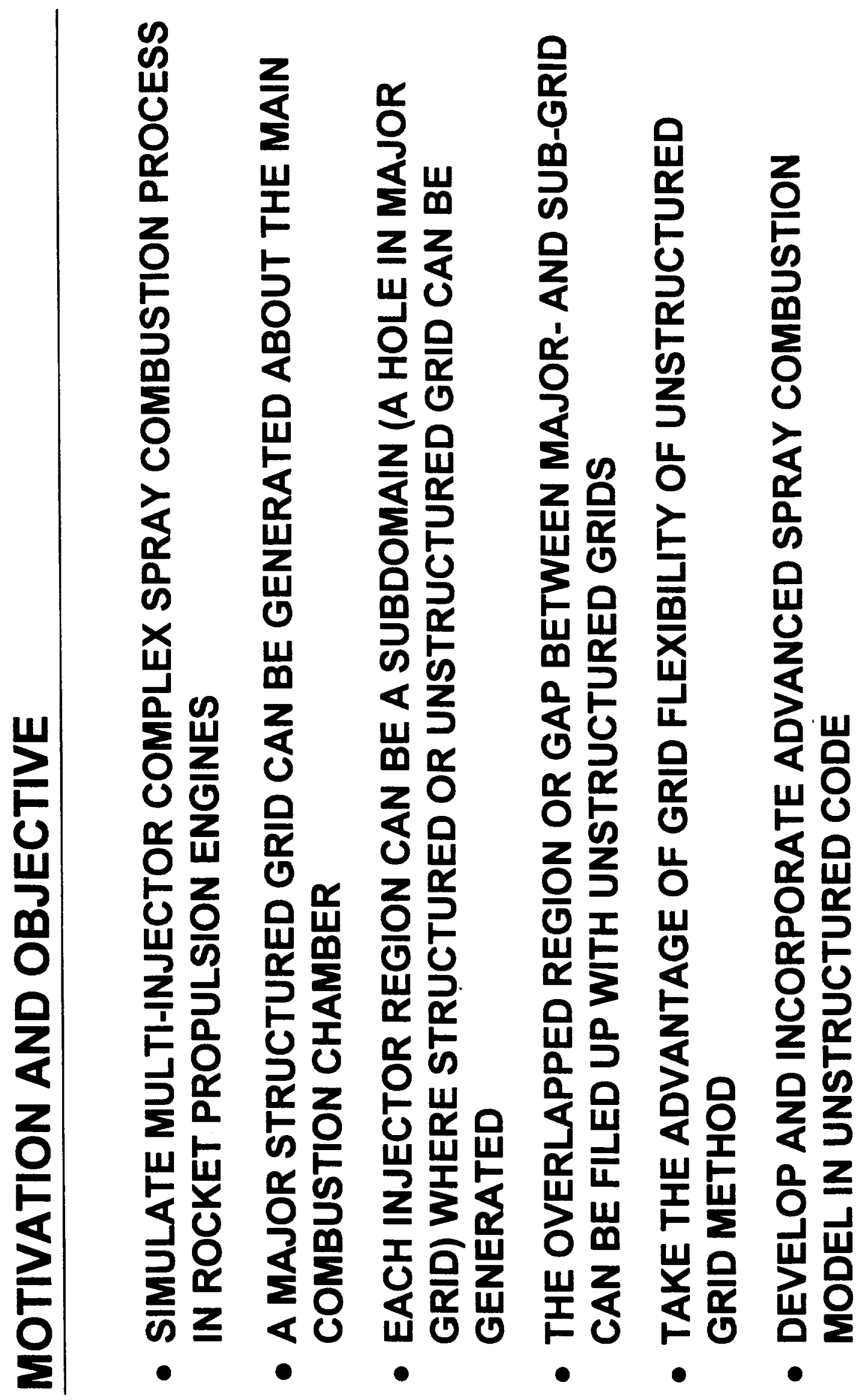

בัँ 


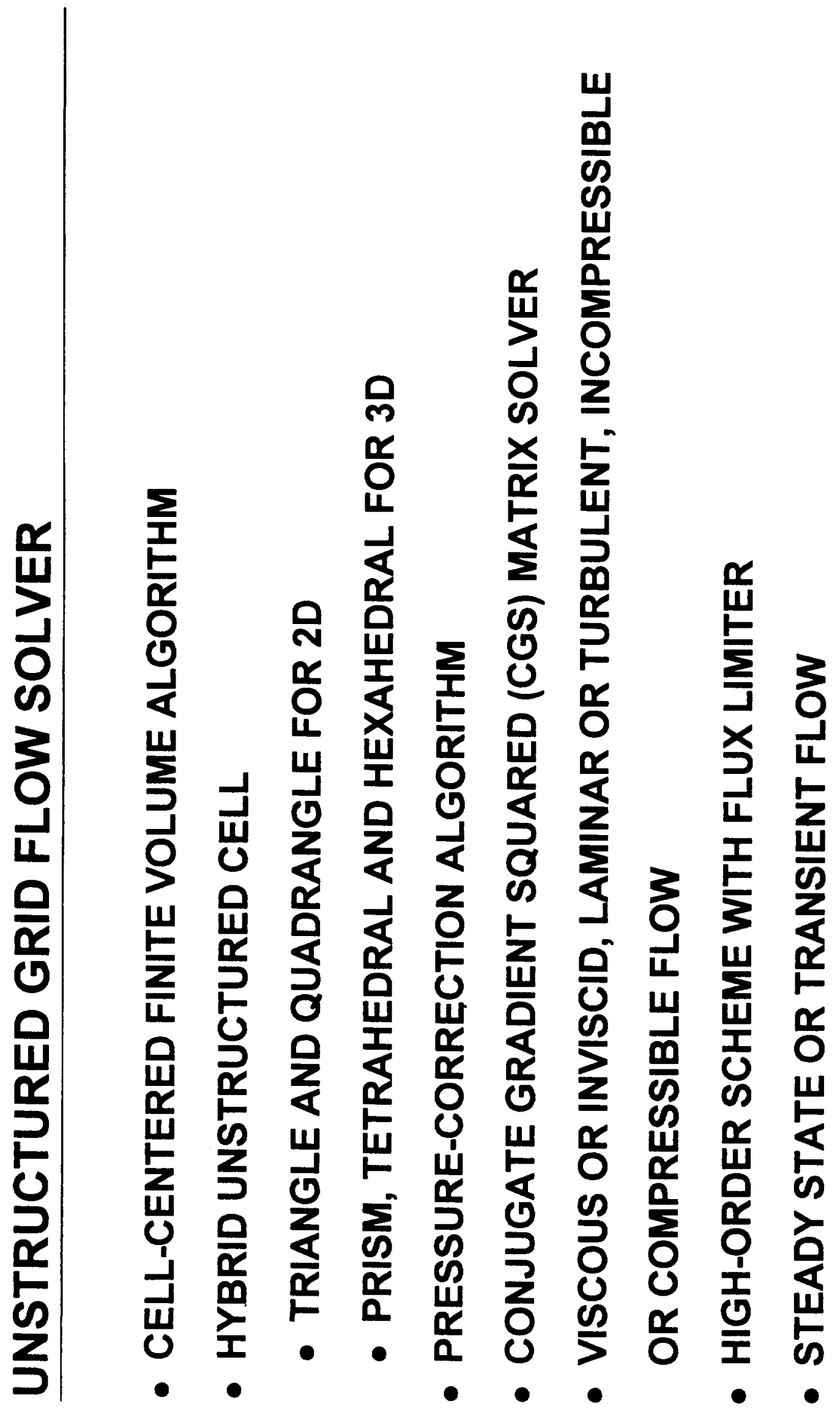



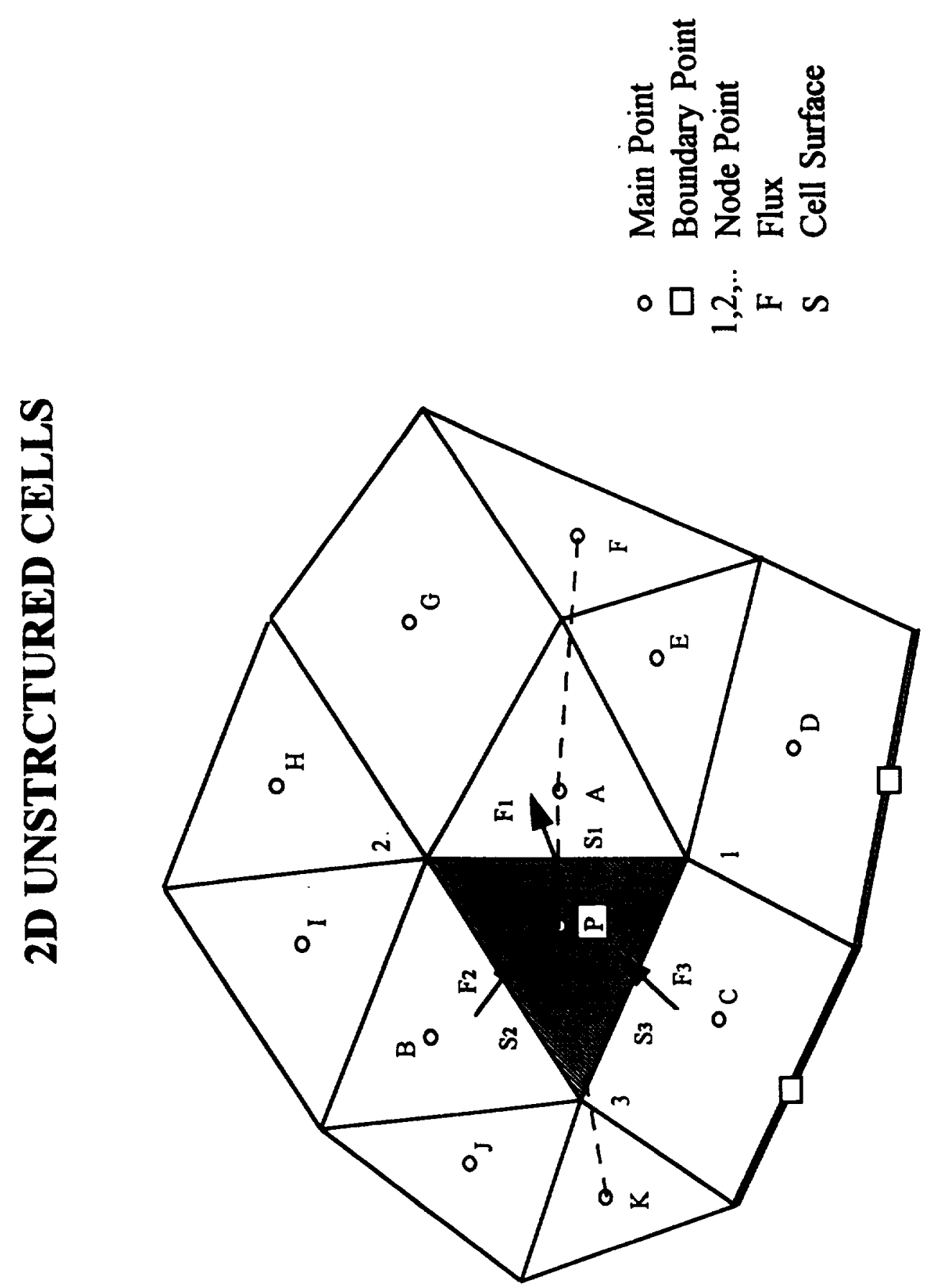


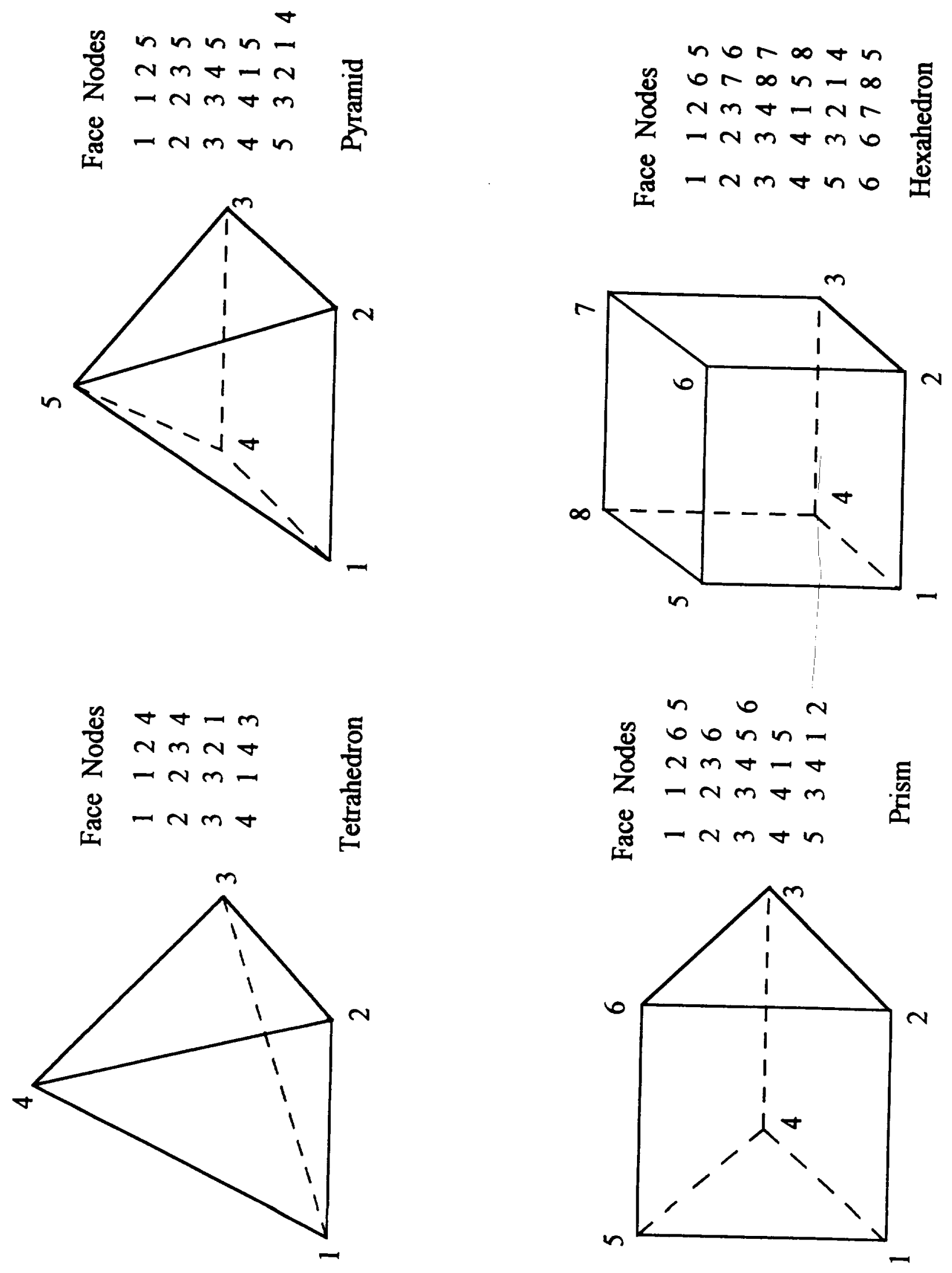




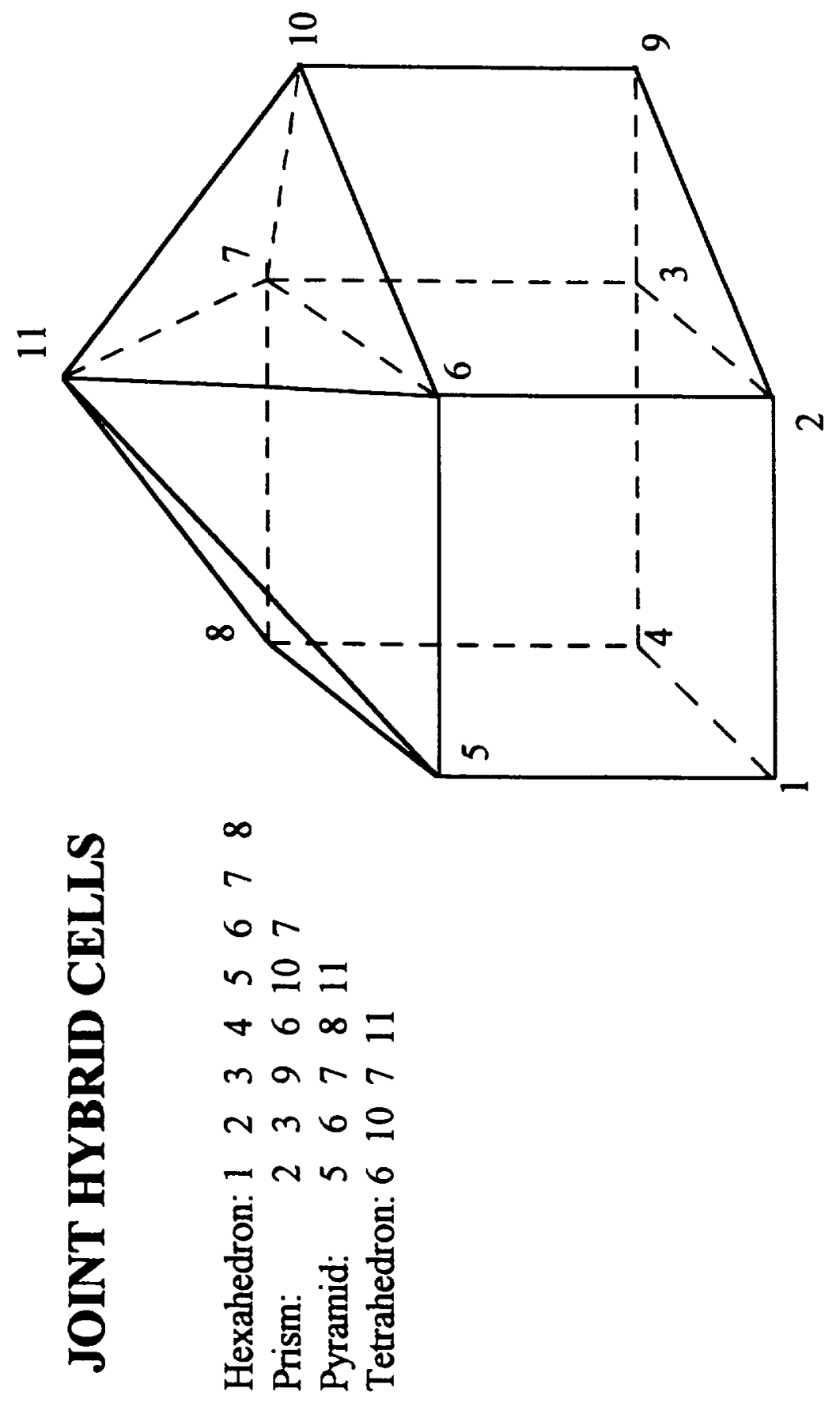




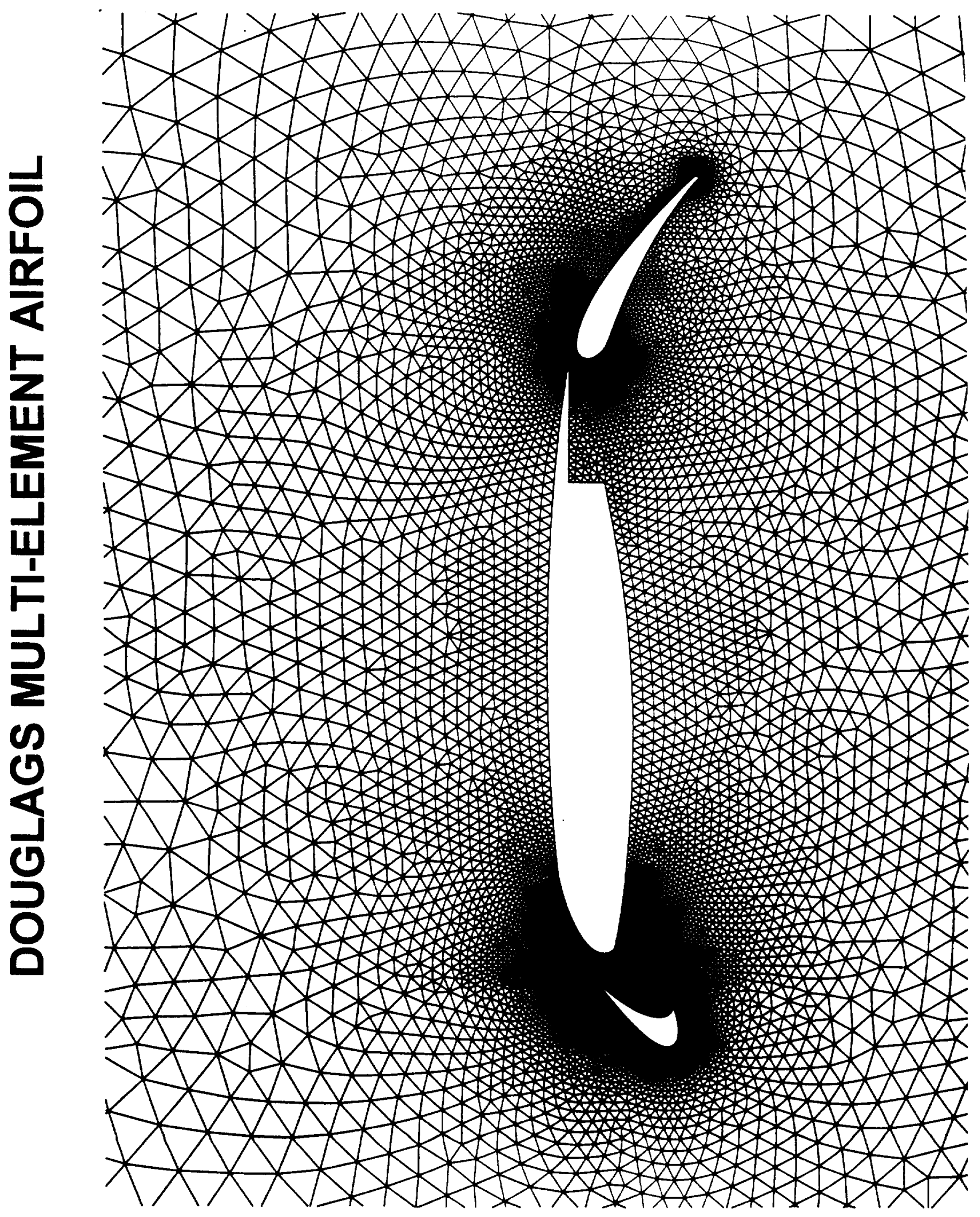




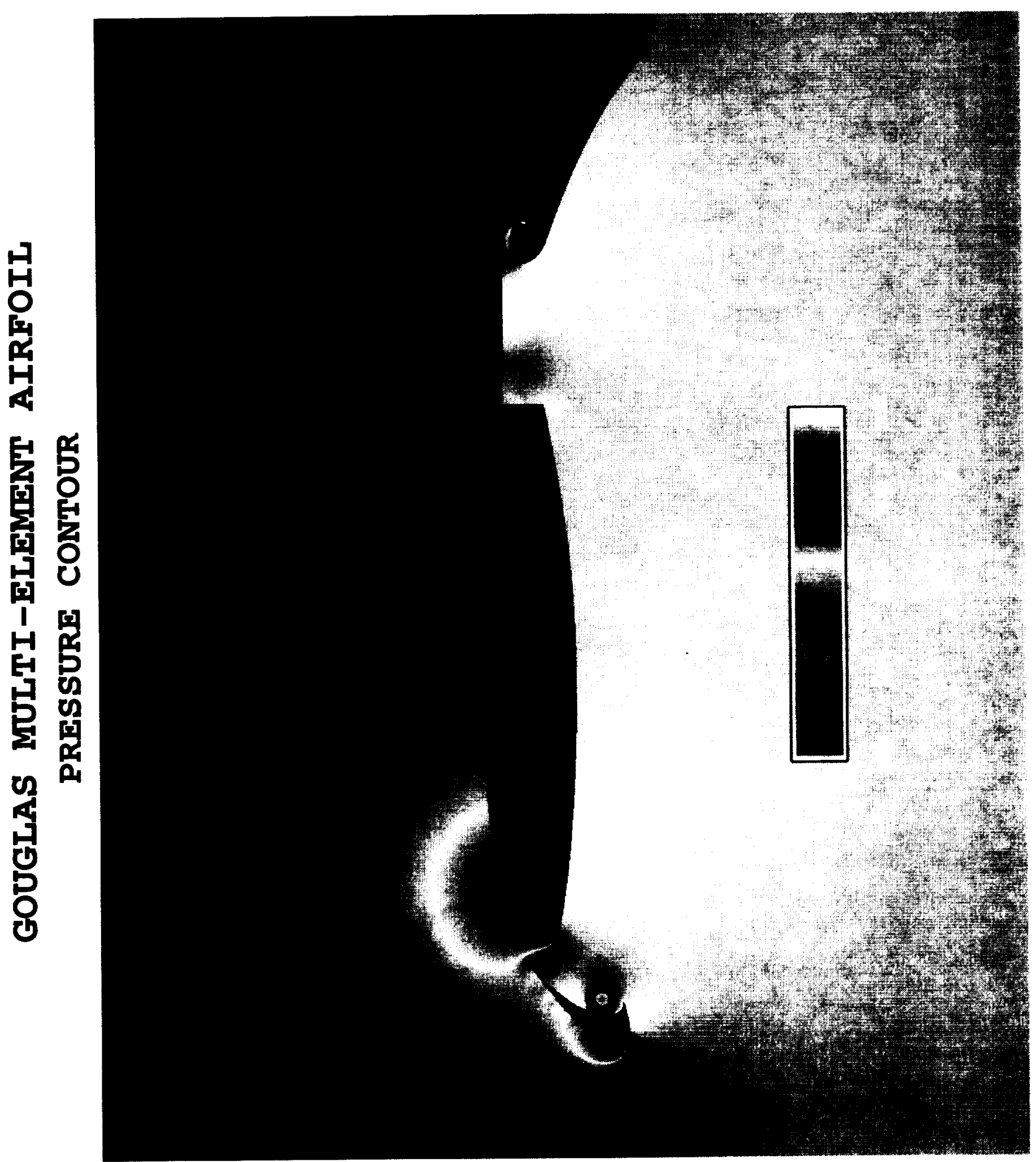




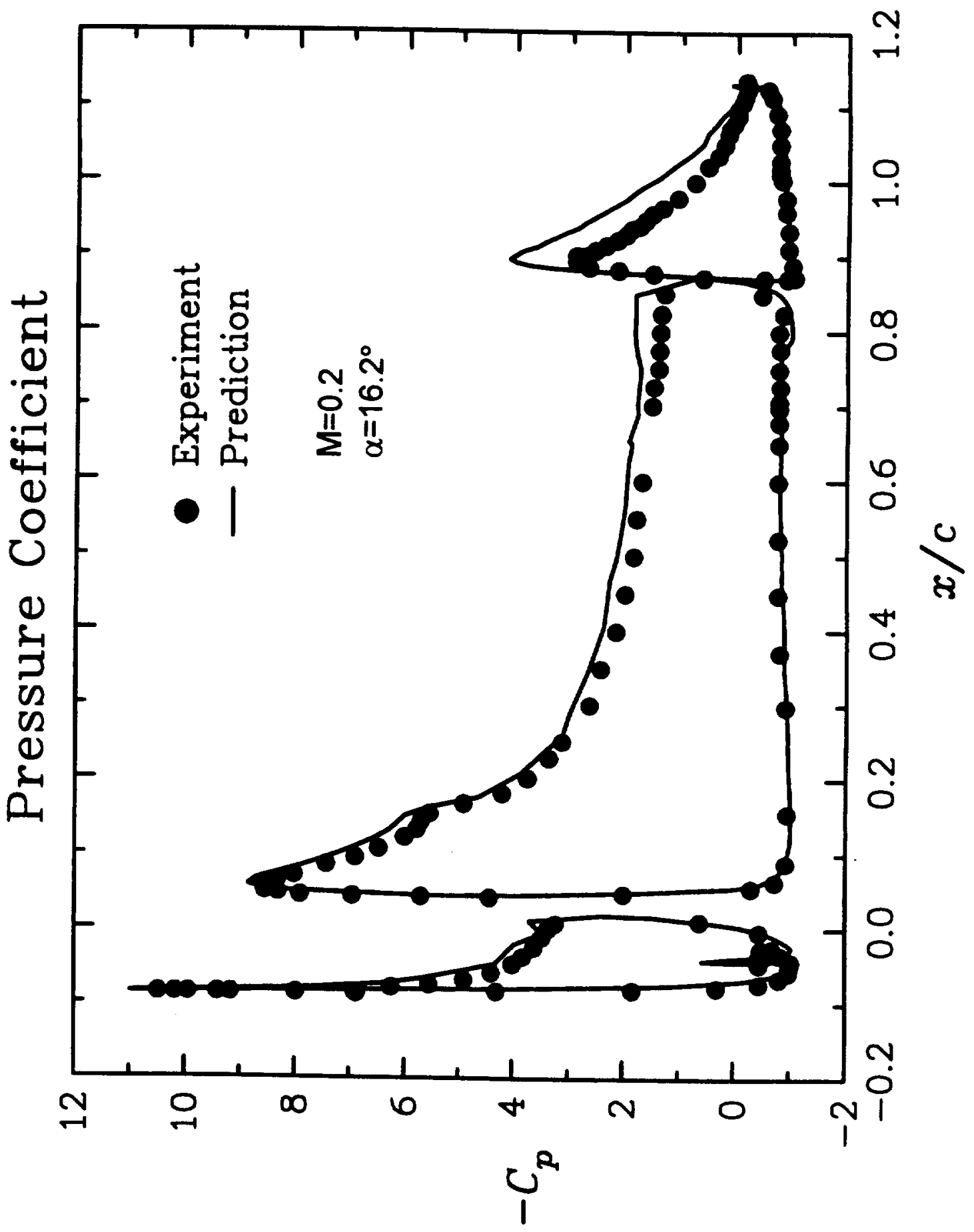




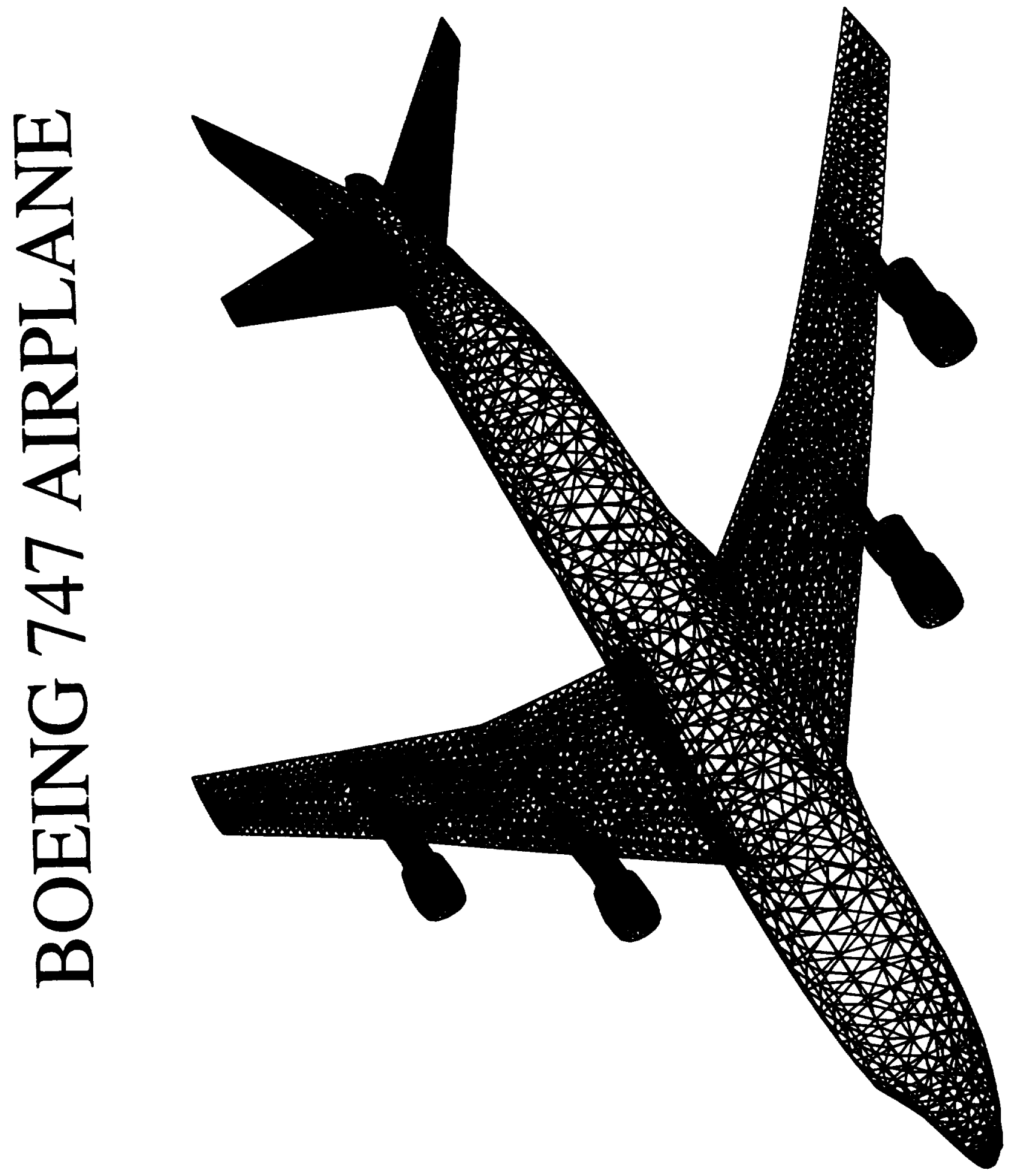




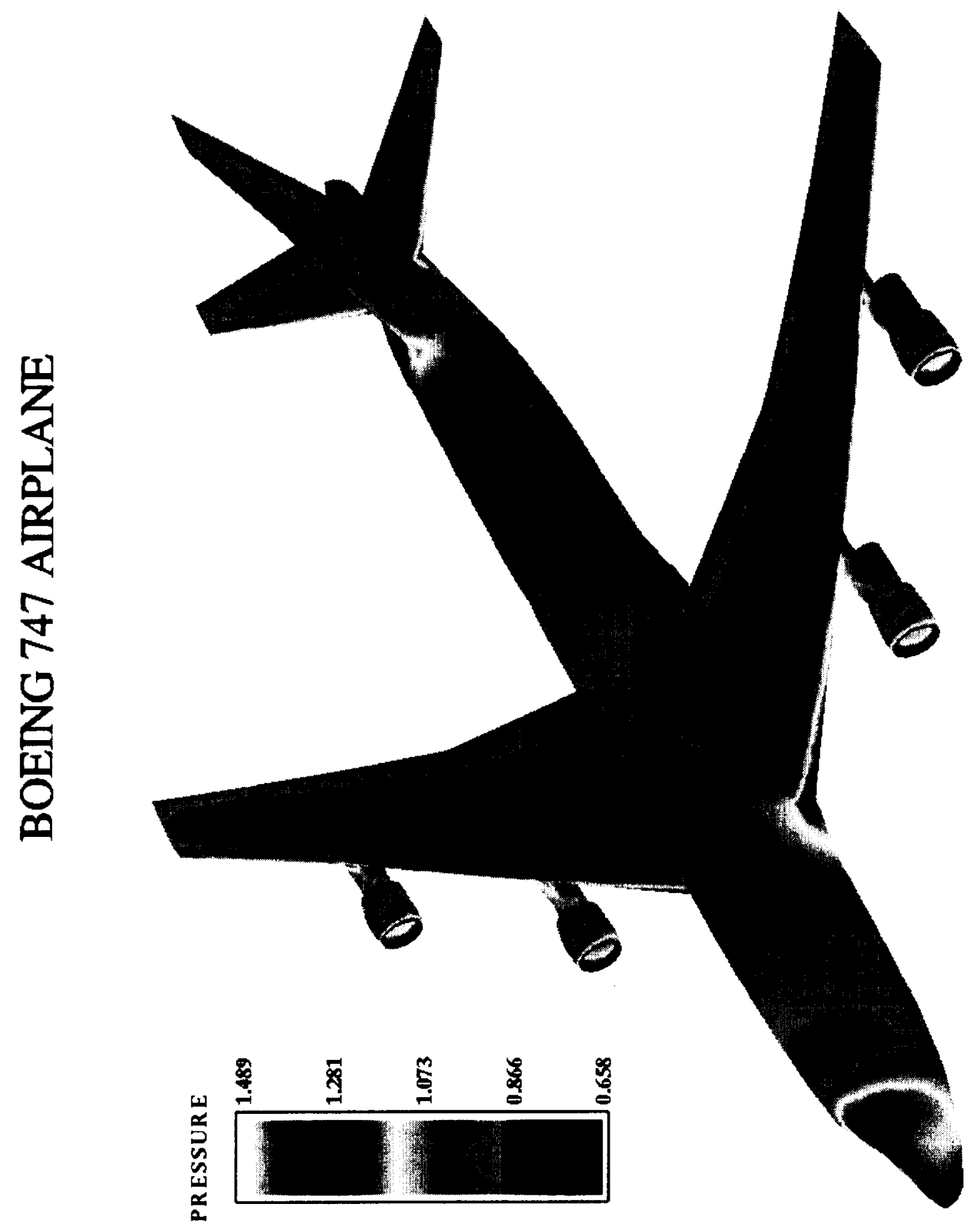



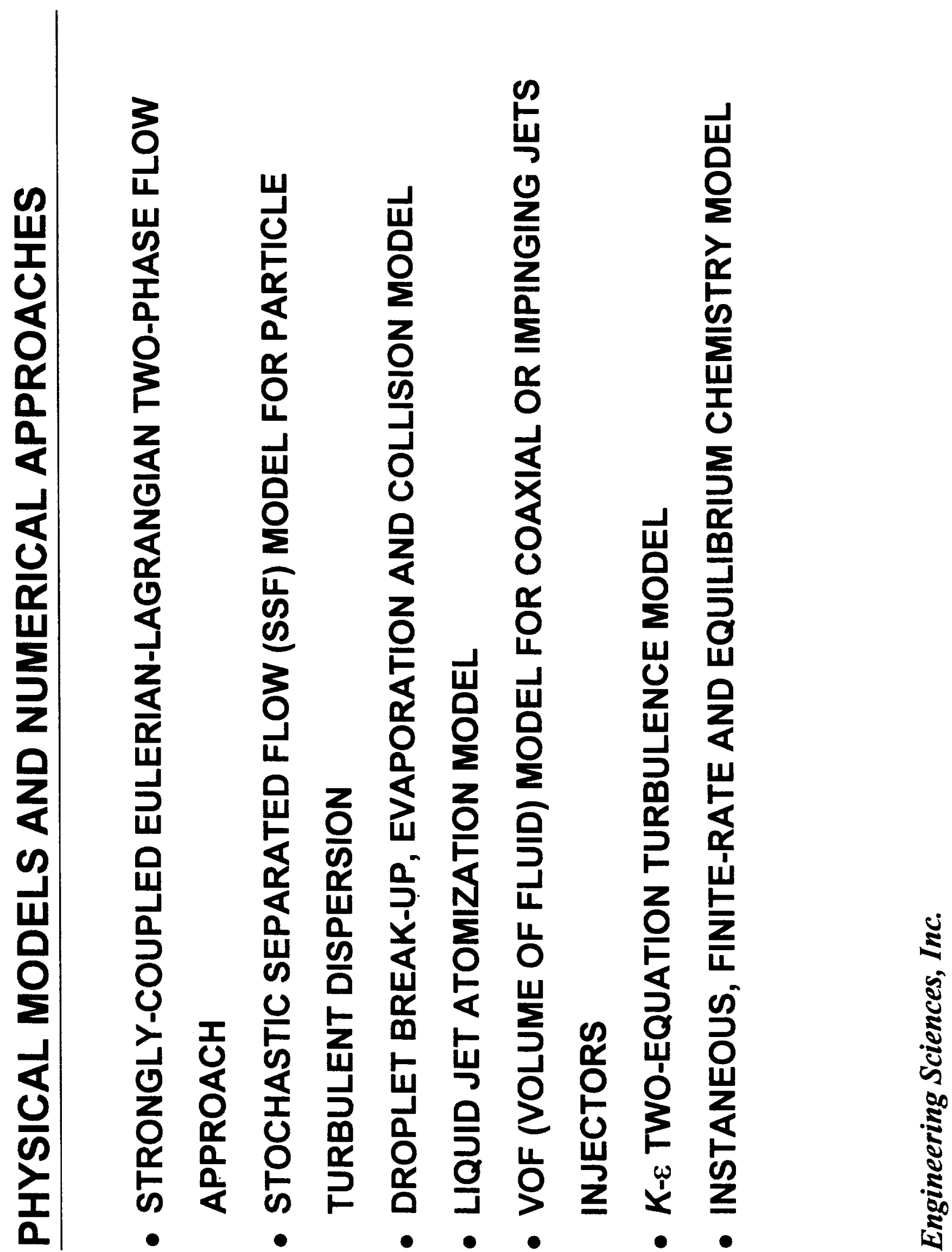


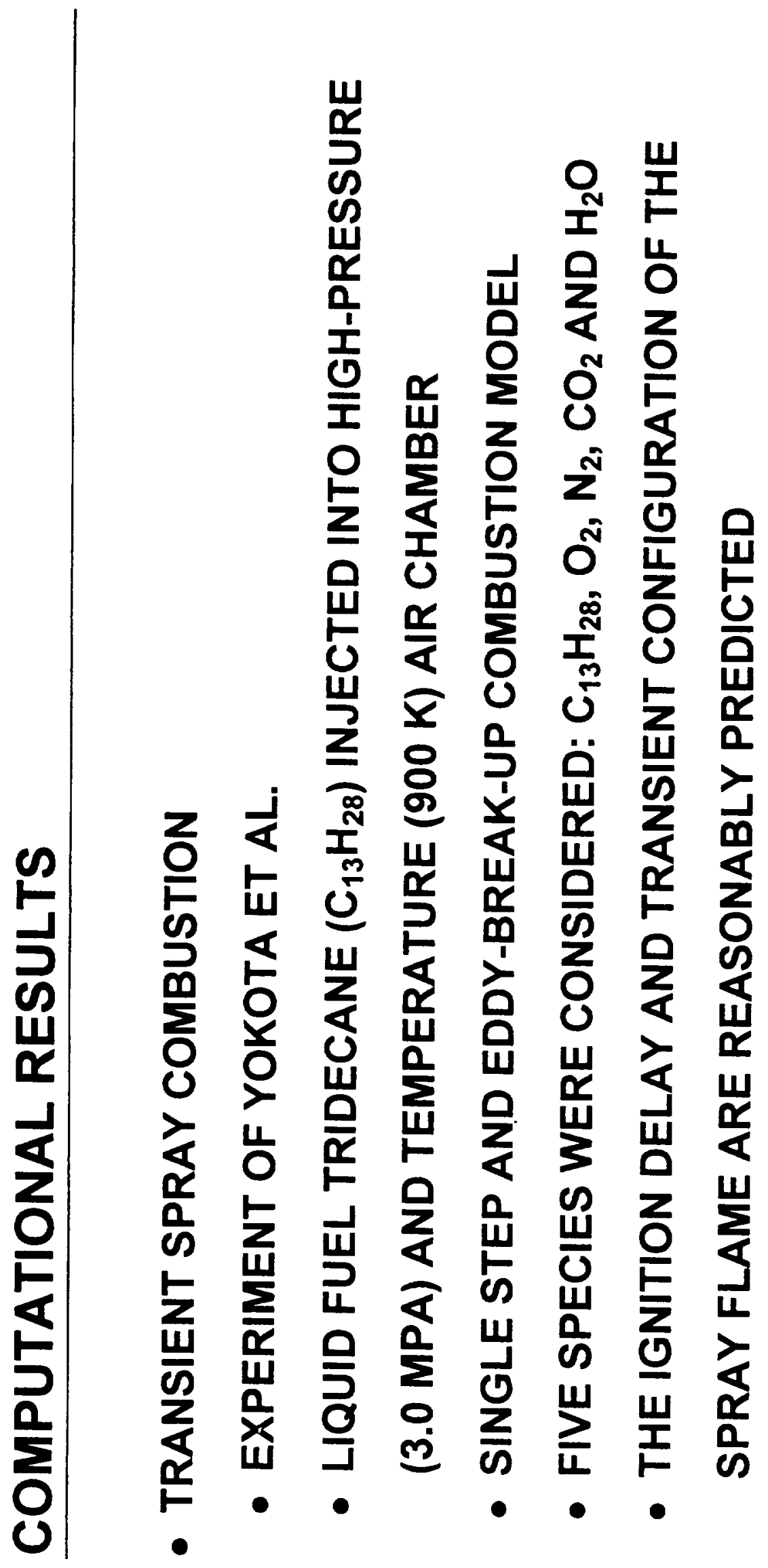

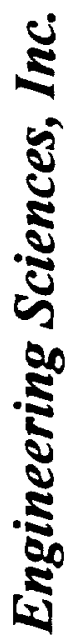




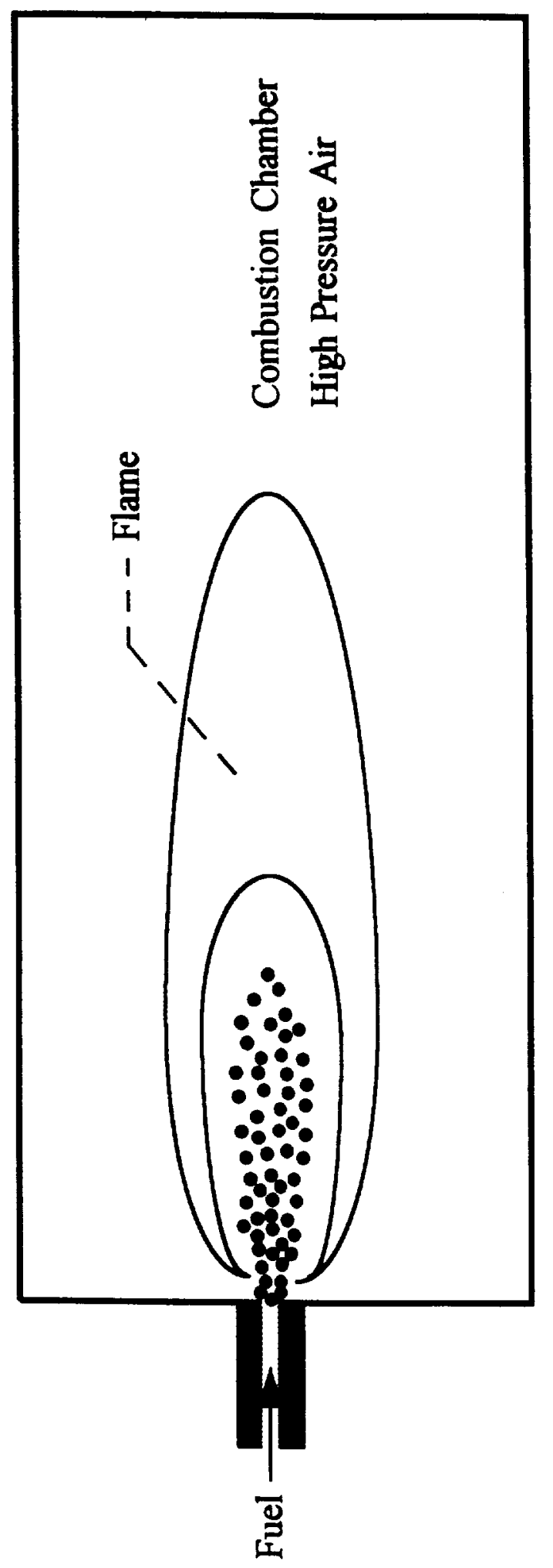




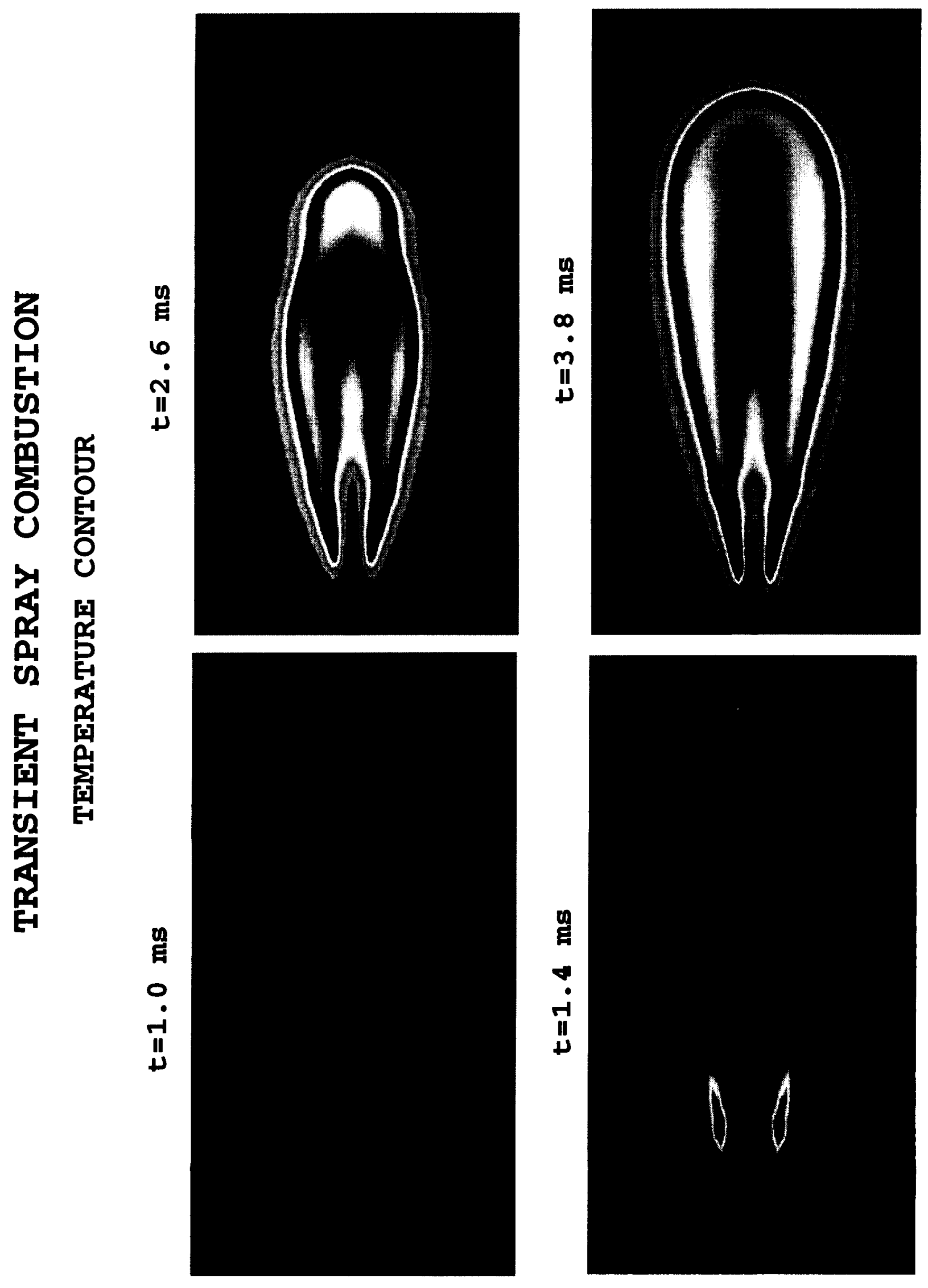



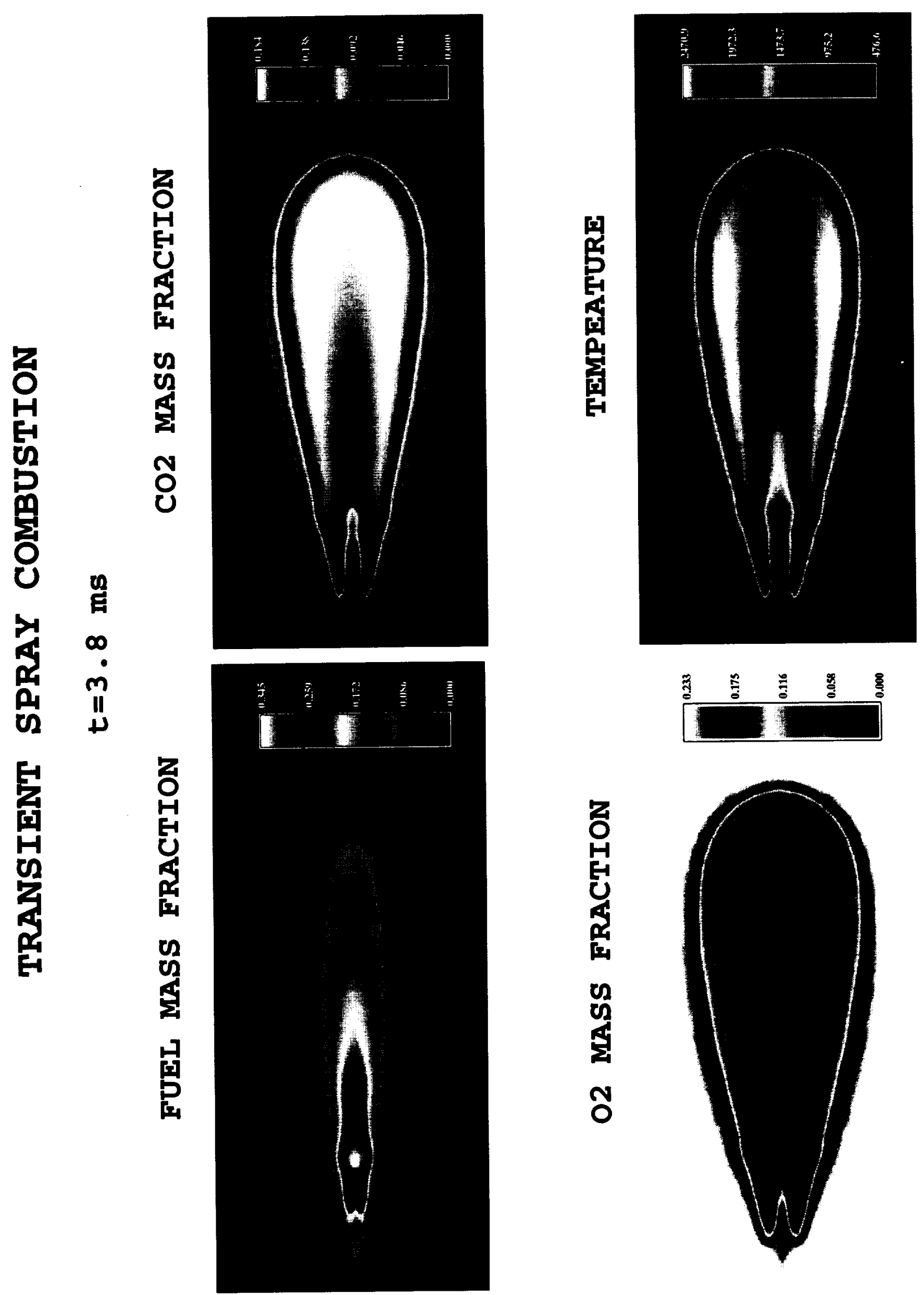


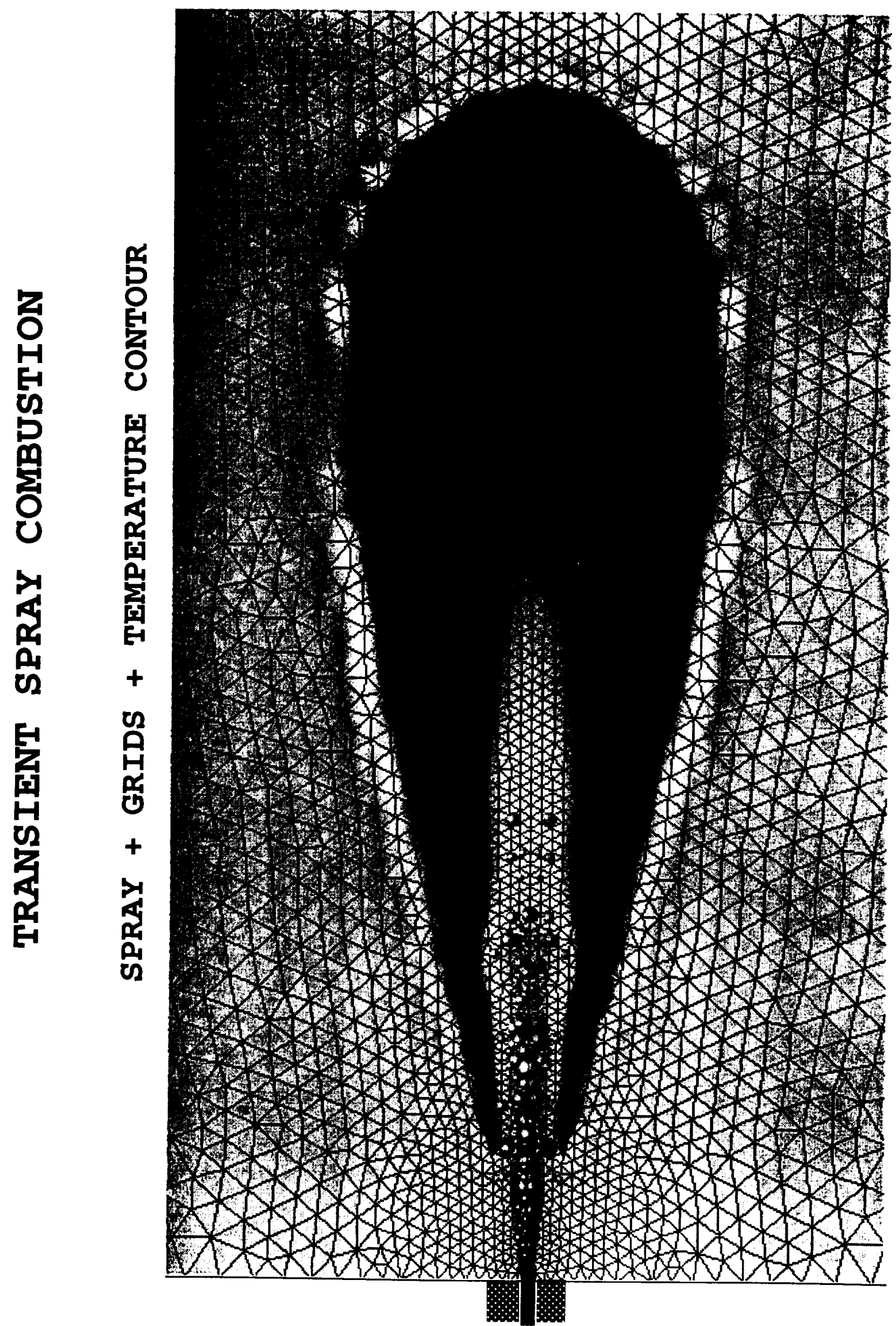




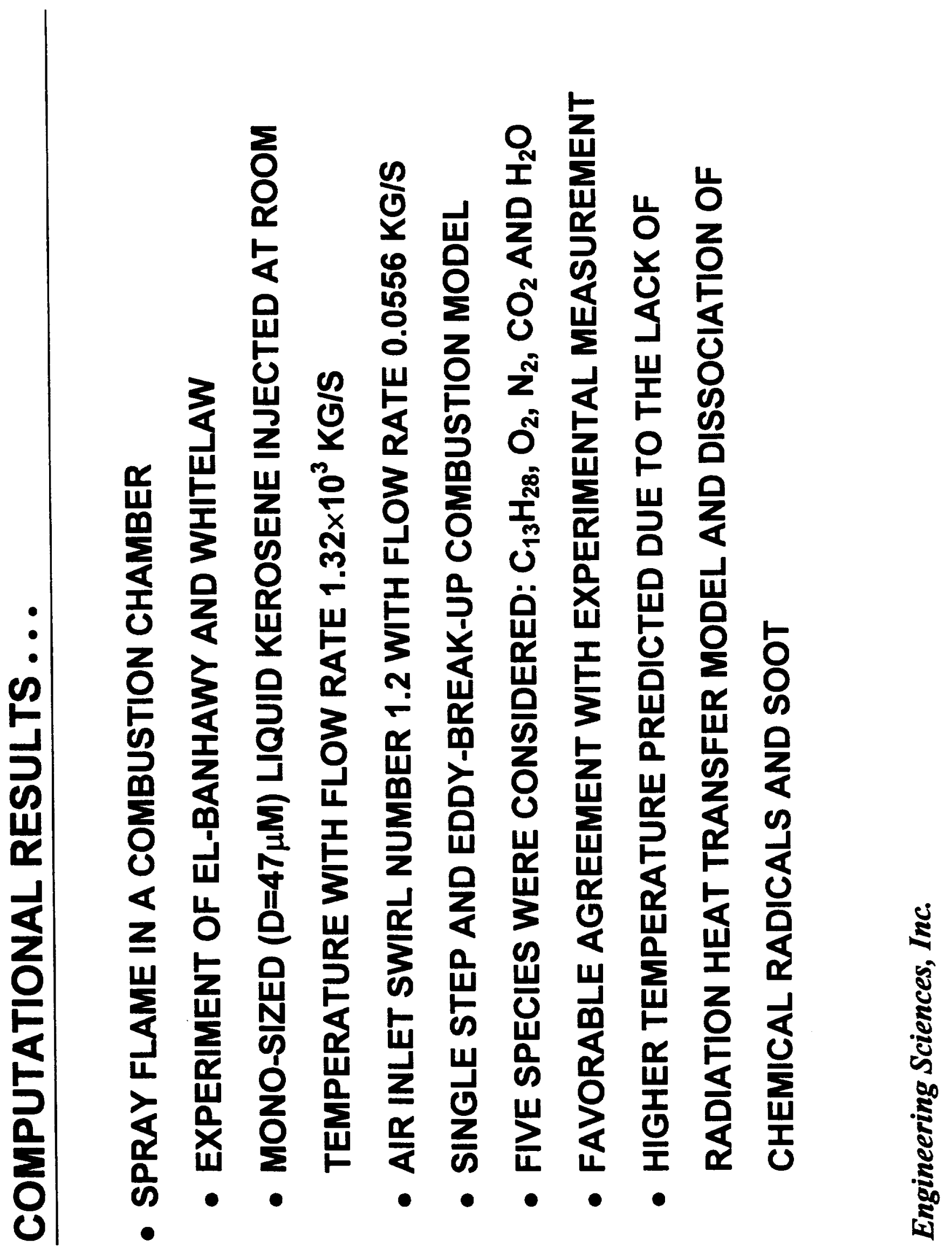




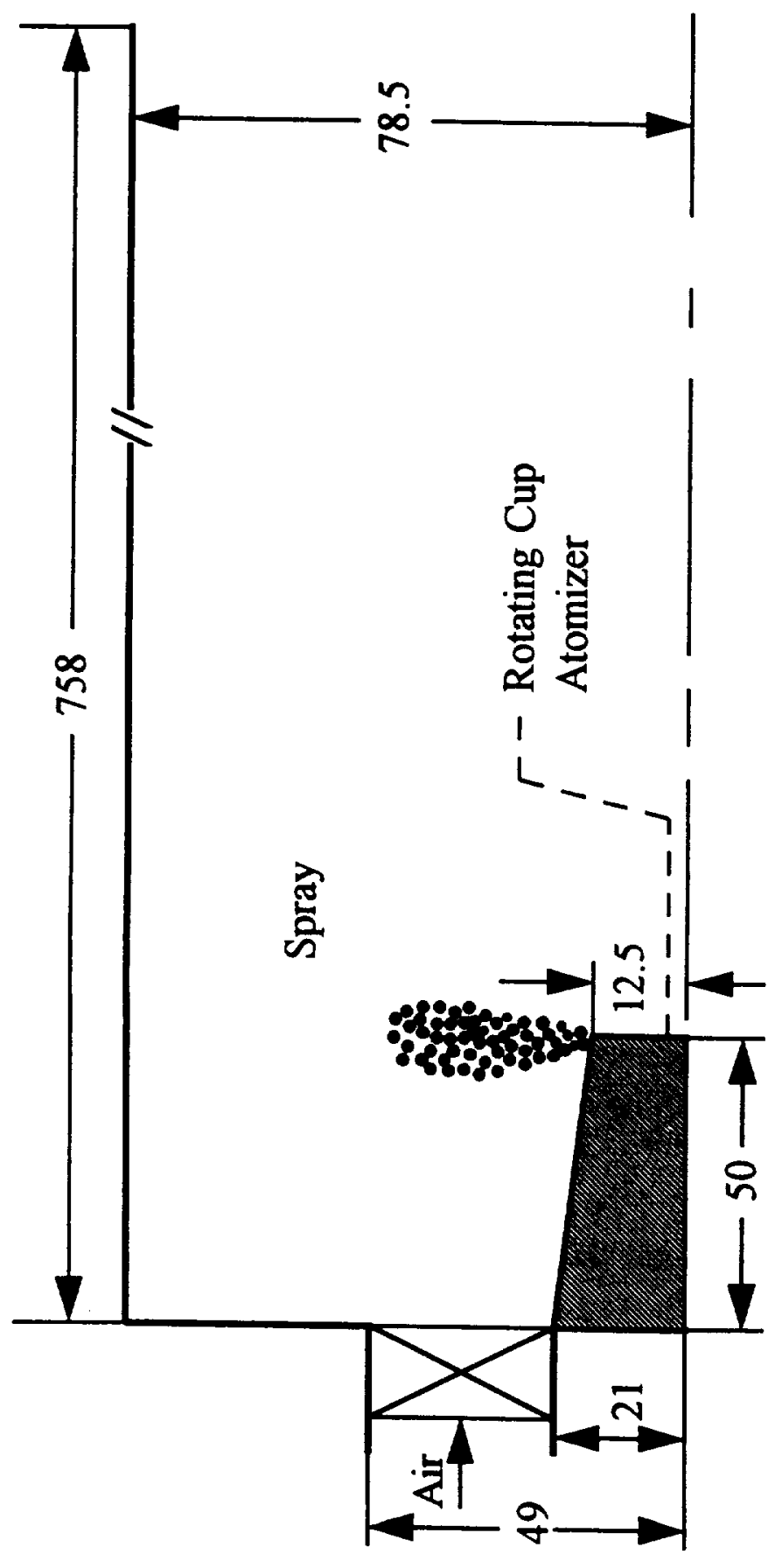



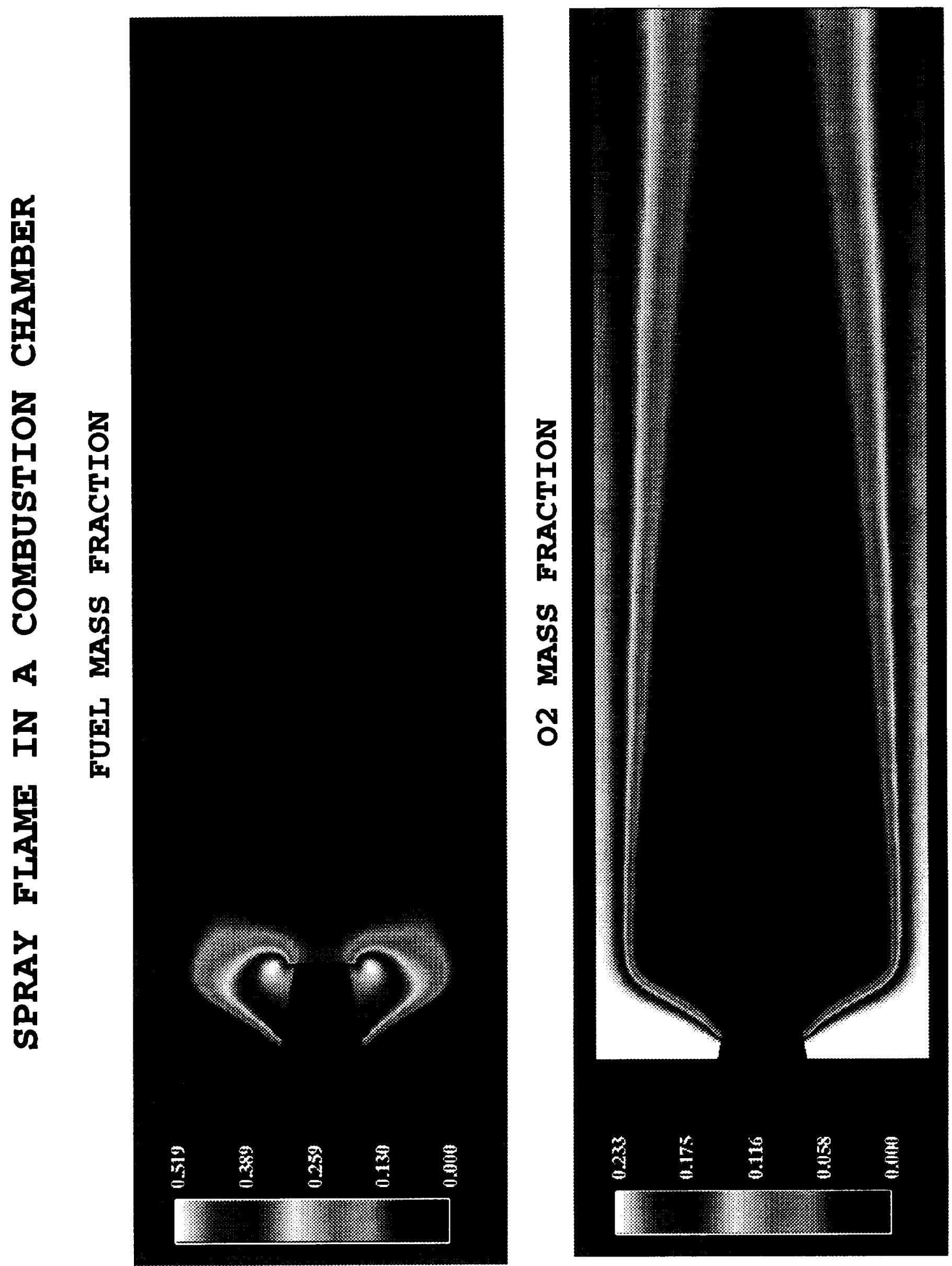

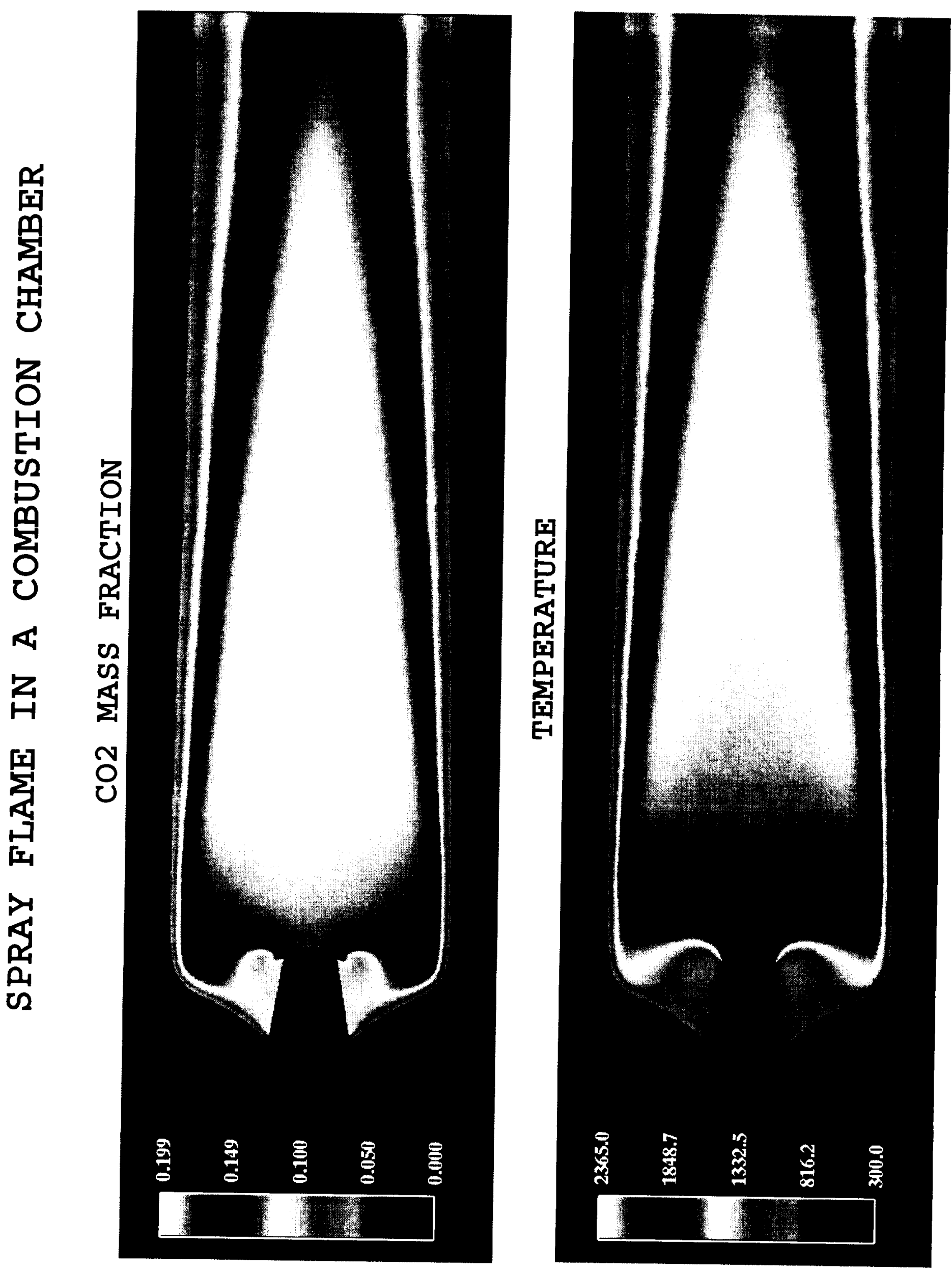


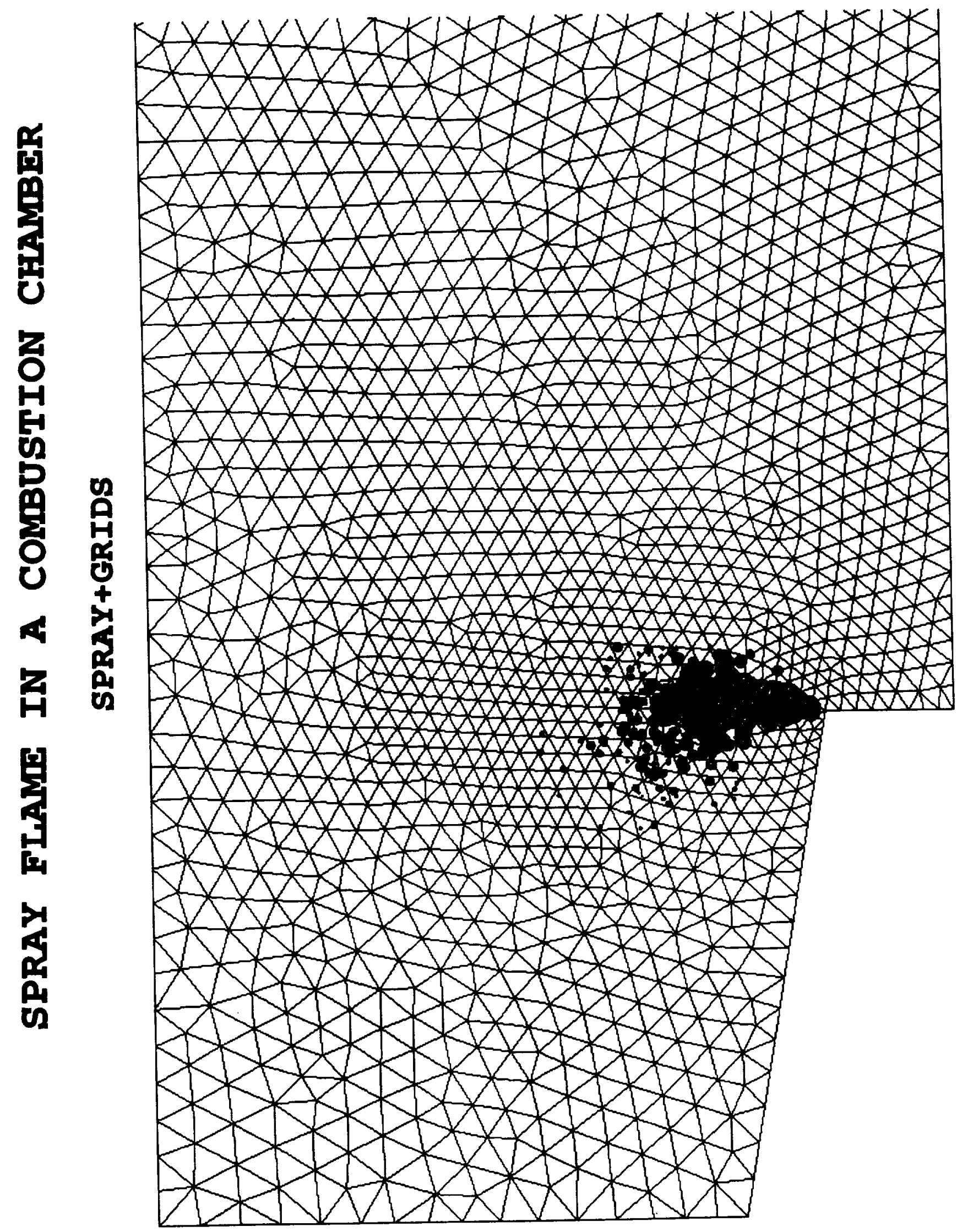




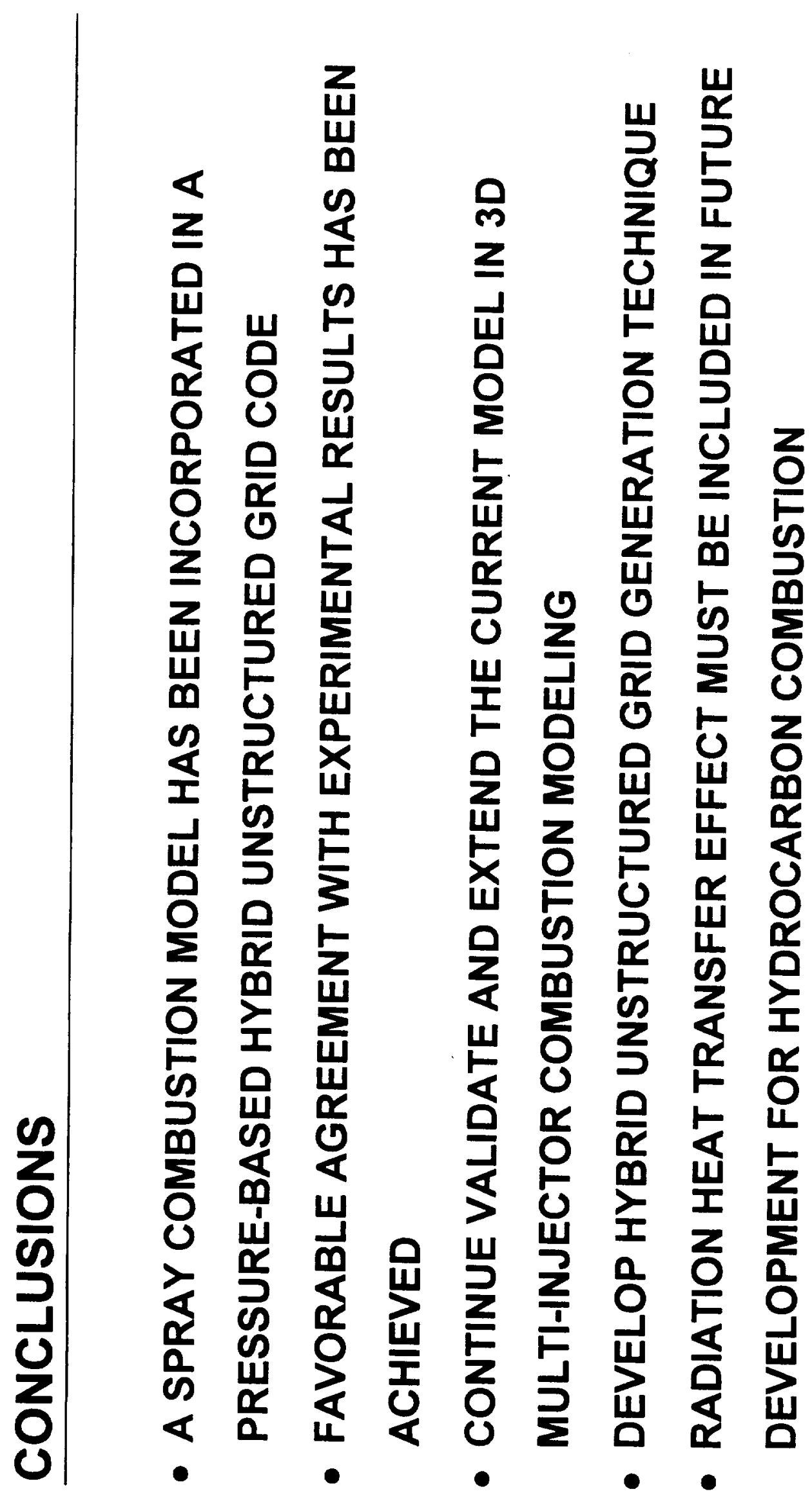


